\title{
Research on process and simulation of the isothermal forging of a spur bevel gear
}

\author{
Zhao Xinhai ${ }^{1,2, a}$, Zhao Liangang ${ }^{1}$, Tian Zhirui ${ }^{1}$, Liu Chuanjin ${ }^{1}$, and Wu Xianghong ${ }^{1}$ \\ ${ }^{1}$ Key Laboratory of Liquid-Solid Structural Evolution \& Processing of Materials, Ministry of Education, \\ Shandong University, Jinan, Shandong, 250061, PR China \\ 2 State Key Laboratory of Materials Processing and Die and Mould Technology, \\ Huazhong University of Science and Technology, Wuhan Hubei, 430074,PR China
}

\begin{abstract}
This paper took the lead in applying isothermal forging technology to form a spur bevel gear in a single operation. According to the isothermal forging process, the forging part drawing of the spur bevel gear was defined. The $20 \mathrm{CrMnTi}$ was chosen as the gear materials. A closed-die structure was used in the forging process. Then, the model of the dies and workpiece were built by UG software. After the models was imported into DEFORM-3D, the simulation of the isothermal forging process of the bevel gear was executed. Through simulation, the shape of the gear, the distributions of effective stress and strain, the forming load of the dies, the laws of metal flow and the filling of the metal during the forging process were gained and thoroughly discussed. The results revealed that the full forging process can be divided into four periods and precision spur bevel gear can be obtained without causing under-filling and folding defect by using the isothermal forging with closed-die forging structure, which provides guidance to manufacturing the spur bevel gear.
\end{abstract}

\section{Introduction}

Straight tooth bevel gears have been widely applied in automobile, agricultural machinery, engineering machinery, etc. According to the difference in deformation temperature of billet, the precision forging technology can be divided into hot precision forging, cold precision forging, warm forging and isothermal forging ${ }^{[1]}$.

Since the precision forging gear process was derived from Germany in the 1950s, many gears have been manufactured with less or no cutting processing and the precision of gears can reach $0.02 \sim 0.05 \mathrm{~mm}^{[2]}$. However, when it comes to the current precision forging, there are still a great number of problems in actual production ${ }^{[3-4]}$.

1, Resistance of deformation is so large that it is necessary to carry out intermediate heat treatment and superficial treatment in the cold forging process;

2,It is easy to result in the reduction of accurate dimension and surface quality due to the strong oxidation in hot forging;

3,Although warm forging overcomes the drawback of cold forging and hot forging, requirement for equipment is higher.

In addition, it is easy to cause a small amount of shrinkage after cooling and there are difficulties in forming gears in a single forging operation.

Based on the above problems, experimental and theoretical analysis in the forming of spur bevel gears have been carried out. Summarily, the forming technology for spur bevel gears were more considered in the research. Lin et al. ${ }^{[5]}$ studied and analyzed the cold extrusion process and fabrication technology for a differential bevel gear. Grzegorz Samołyk ${ }^{[6]}$ and Deng et al ${ }^{[7]}$ studied both a theoretical and experimental investigation of the cold rotary forging process of a spur bevel gear. $\mathrm{W}$. Bochniak et $\mathrm{a}^{[8]}$ investigated the forging process by the KOBO method and employed this method in forming a spur bevel gear to obtain forge piece with complete formation of the teeth under less forming force. Song ${ }^{[9]}$ carried out the process design for closed-die forging of bevel gears using 3-D FEM simulations. Nevertheless, flash in the gear and fracture on the punch were occurred due to the over punch stroke during forming process.

Isothermal forging, which is conducted under the condition of lower strain rate and the constant temperature between the die and billet ${ }^{[10]}$, has many advantages such as small working allowance, high precision and low residual stress. But few researchers have carried out investigation on applying isothermal forging to form spur bevel gears because it is difficult to ensure the die and billet to remaining high deformation temperature for a long time and the die trend to soften under high temperature. However, in recent years, with the rapid development of isothermal forging technology of titanium alloy, the heat insulation device and die material ${ }^{[11]}$ can be employed in isothermal forging of gear steel 20CrMnTi. To ensure the precision of the simulation, the mechanical properties under low temperature of $20 \mathrm{CrMnti}$ was gained by a series of

a Corresponding authors: xhzhao@sdu.edu.cn 
experiments. Moreover, several researchers constantly developed die materials for isothermal forging, such as $\mathrm{N} 3^{[12]}$ and $\mathrm{DM} 02^{[13]}$, which provides a possibility to form bevel gears by isothermal forging.

This paper carried out the research on the isothermal forging process of the spur bevel gear by using the FEM simulation method. The metal flow, forming load and the deforming field valuables during the forging process were obtained.

\section{FEM simulation models}

The part drawing of a straight tooth bevel gear is shown in Figure 1.

Figure 1. Part drawing of the gear

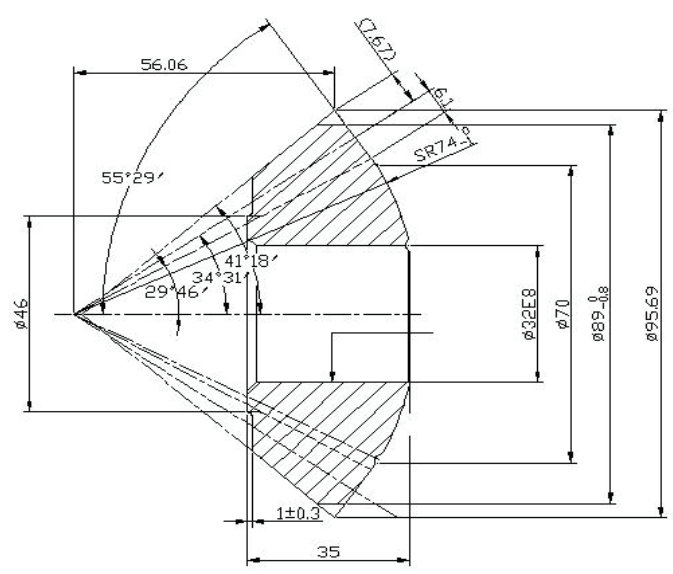

The die structure used in this current study is closeddie forging. According to the final forging drawing, three dimension model of die and billet at the proper position was established using UG software. Then, the STL file of the models were transferred by UG and introduced into Deform-3D to carry out numerical simulation. Meanwhile, the material property of workpiece was defined, which is based on the constitutive equation obtained before and mechanical properties of 20CrMnTi under isothermal spheroidisation(shown in table 1) ${ }^{[7]}$. The finite element model is shown in Figure 2, which takes one tenth of the entity to calculate for the sake of improving simulation accuracy and save calculation time. In this model, both the upper die and the lower die were made by two parts. At the beginning, the upper punch and the top die move down in the same velocity until the upper die comes into contact with the bottom die, therefore, a closed cavity has been formed. Then, the upper punch continues moving down and the bottom punch begins to move upwards at the same speed as the upper punch, which contributes to making metals flow into the cavity.

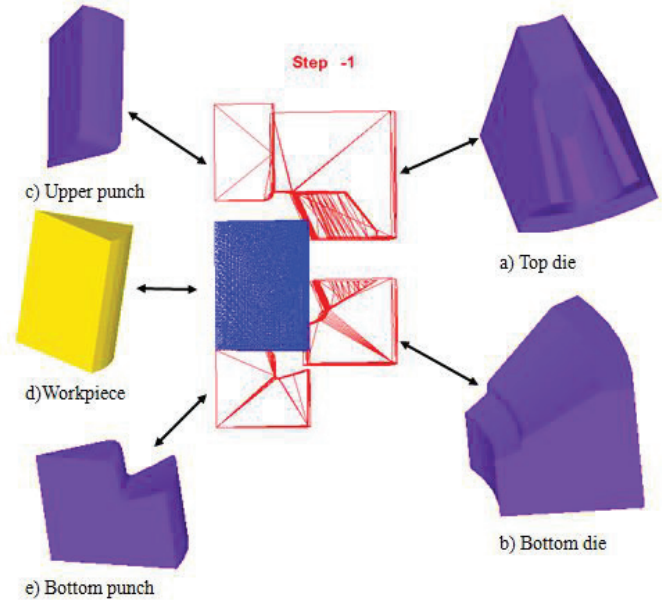

Table 1. Mechanical properties of 20CrMnTi under isothermal spheroidisation.

\begin{tabular}{ll}
\hline Heat treatment mode & \multicolumn{1}{c}{$\begin{array}{c}\text { Isothermal } \\
\text { spheroidisation }\end{array}$} \\
\hline Poisson' s ratio & 0.3 \\
Density $\left(\mathrm{kg} / \mathrm{m}^{\wedge} 3\right)$ & 7800 \\
Yield strength $(\mathrm{MPa})$ & 325.68 \\
Ultimate strength(MPa) & 521.17 \\
Young' s modulus $(\mathrm{GPa})$ & 225.5 \\
\hline
\end{tabular}

In addition, the general conditions for the finite element model are summarized in Table 2.

Table 2. The general conditions for the finite element model

\begin{tabular}{ll}
\hline Condition & Description \\
\hline Deformation temperature & $900{ }^{\circ} \mathrm{C}$ \\
Workpiece & plastic \\
Dies & rigid \\
Velocity of dies & $0.05 \mathrm{~mm} / \mathrm{s}$ \\
Friction model & Shear friction \\
Friction between dies and & 0.3 \\
workpiece & \\
Number of elements & 50000 \\
\hline
\end{tabular}

\section{Simulation results and discussion}

\subsection{Analysis of defects and load prediction}

Figure 3.presents the spur bevel gear obtained by numerical simulation by Deform-3D. From Figure 3., it can be observed that the spur bevel gear can be formed without causing under-filling because of the closed-die forging manner, meanwhile folding defect does not appear, which can be explained for lower feed rate. Though there are burrs appeared at the clearance between dies and punches, it's size was thin and small and can be removed easily. 


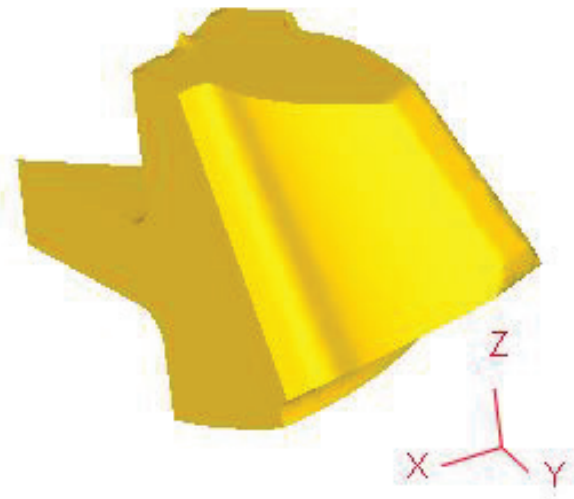

Figure 3. The bevel gear obtained by simulation

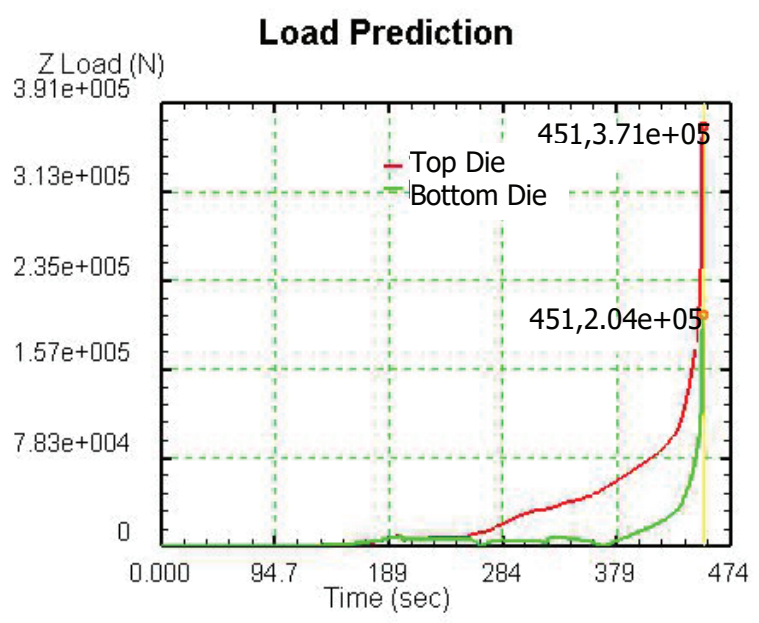

Figure 4. Forming load of top die and bottom die

Figure 4. gives the forming load of top die and bottom die during the isothermal forging. Since the beginning of forging process, the forming load generally keep in lower value with slow-growing. Until the metal begins to flowing into the cavity of big end teeth, the axial forging force sharply increases in the same exponential due to the great metal flow resistance of complete filling of die cavity. In general, compared with the other forging process, the forming force of isothermal forging may be more advantageous. This can be owing to the fact that lower feed rate contributes to the flow and dynamic recrystallization of metal in the process of forming, which leads to less deformation resistance and less forming force. When it comes to the top die whose forming load is higher than other die and punches, its maximum forming load is only $371 \mathrm{KN}$.

\subsection{Analysis of metal flow}

The velocity field obtained by DEFORM -3D is shown in Figure 5. According to the difference in the direction of metal flow, there are four periods during the whole forging process. At the first period(Figure 5a), namely in the very beginning of the forging process, most of metal move downward and the billet presents upsetting deformation due to downward pressure from the upper die and punch. Then, after the top die comes into contract with bottom die, the metal begins to flow inside the cavity and metal flow is mainly in radial direction, and this is the second period(Figure.5b). At the third period(Figure. 5c), with the increase of reduction and contract area, when the billet has contract with the small tooth section of top die, metal begins to flow in the upper right direction. In the next, as a result of the resistance from the contract surface, flow direction of the metal in the center of billet happens to offset lengthways while flow direction of the teeth offsets clockwise. At the final finishing period(Figure. 5d), the metal mainly flows along the normal direction of the cavity, which helps to cause the complete filling of die cavity.
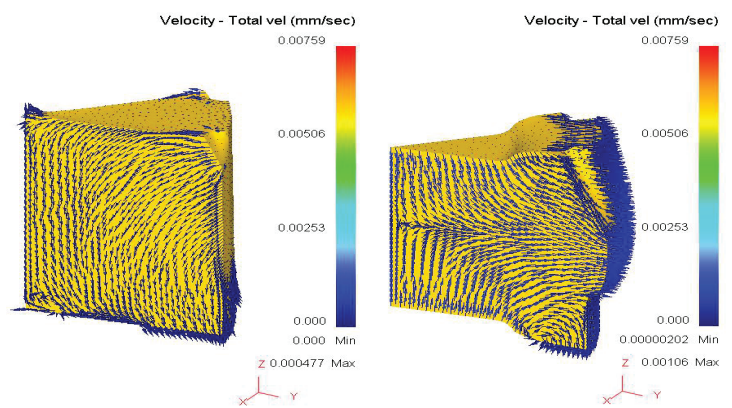

(a) first period

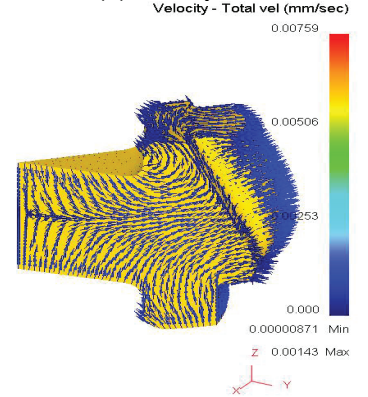

(c) third period

(b) second period

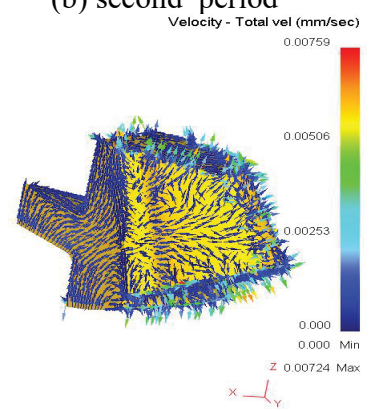

(d) fourth period

Figure 5. The distribution of velocity field during the isothermal forging

\subsection{The distribution of stress and strain}

The distribution of effective strain and stress at different time during the isothermal forging process is shown in Figure 6 . It can be seen from Figure 6 . that, the evolution of effective strain and stress is similar with those of the forming load in the whole isothermal forging, which also can be described as the following two periods. At the end of the first period, as shown in Figure 6.(a) and Figure 6.(c), the effective strain and stress (20 55 Mpa) basically maintain in lower value with a little change. When the metal begins to flow into the cavity of big end teeth, the second period started. At the end of the second period, as shown in Figure 6.(b) and Figure 6.(d), the strain and stress rapidly increase up to 4.91 and $282 \mathrm{Mpa}$ respectively since the metal is pressed against the wall of the die cavities. Moreover, the larger strain and stress locate in the edge areas of end face and tooth crest in the forged gear, which reveals the metal of this area undergoes the highest degree of deformation. 


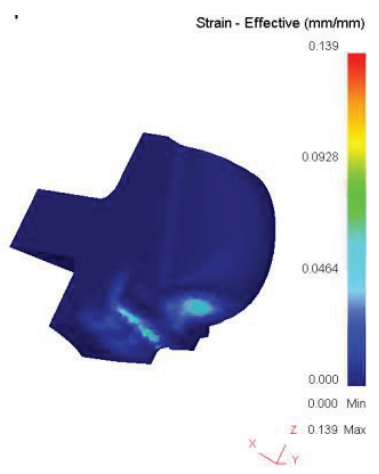

(a) strain of first period

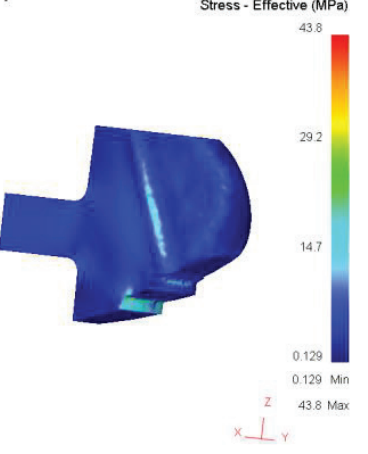

(c) stress of first period

(d) stress of second period

Figure 6. The distribution of effective strain and stress during the isothermal forging

\section{Summary}

This paper conducted the simulation of the isothermal forging process of spur bevel gear by using the FEM method. The following conclusions can be achieved:

1 ,Using the isothermal forging with closed-die structure, the spur bevel gear can be formed without causing under-filling and folding.

2, The forming load of the dies during the isothermal forging process were obtained. The load of the top die is larger than those of the lower die.

3 ,According to the simulation result, the forging progress can be divided into four periods. The velocity, effective strain and effective stress of the every periods during the process were obtained.

\section{Acknowledgements}

This work was financially supported by the fund of State Key Laboratory of Materials Processing and Die \& Mould Technology, Huazhong University of Science and Technology (P2014-11) and The Interdisciplinary training project of Shandong University (2014JC024).

\section{References}

1. Wang X.Y. Metal Proc.;7(2012)20-21.

2. Yuan X. Net shape Forming Engineer. 6(2010)51-59.

3. Wang J.,Li P. J. of Plasticity Engineer. 1(2013) 6-10.

4. Zhao J.H. Metal Proc. 17(2008)14-17.

5. Lin C.,Xu P..Modern Manu. Engineer. 6(2011) 6972 .
6. Samołyk G. J.Mater.Proc. Technol. 213(2013)16921702.

7. Deng X.B., H. Lin.Mater Des. 32(2011)1376 -89.

8. Bochniak W., A. Korbel, R. Szyndler. J. Mater. Proc. Technol. 173(2006)75-83.

9. Song J.H.,Im Y.T.J. Mater. Proc. Technol. 192193(2007)1-7.

10. Zhang Z.L.,Li H.R..Hot Working Technol. (2014):12-15.

11. Guo L.F.,Zhu Y.C.Chinese J. of Rare Material. 2(2012)357-362.

12. ZHAO H.B. ,WU.C.X. Mater. Engineer. 1(2009)1821.

13. Xiao C.B.,Song.J.X. Mater. Engineer. (2005)44-47. 